\title{
Commutation Angle Maps Evaluation for Magnet Arrangements of Interior Permanent Magnet Synchronous Machines in Electric Vehicles
}

\author{
Pedram Asef \\ Dept. of Engineering and Technology \\ University of Hertfordshire \\ Hatfield, United Kingdom \\ p.asef@herts.ac.uk \\ Johannes J. H. Paulides \\ Advanced Electromagnetics Group \\ Waalwijk, The Netherlands \\ johan@ae-grp.nl
}

\author{
Mouloud Denai \\ Dept. of Engineering and Technology \\ University of Hertfordshire \\ Hatfield, United Kingdom \\ m.denai@herts.ac.uk \\ Andrew Lapthorn \\ Dept. of Elec. and Comp. Engineering \\ University of Canterbury \\ Christchurch, New Zealand \\ andrew.lapthorn@canterbury.ac.nz
}

\author{
Bruno Ricardo Marques \\ Advanced Electromagnetics UK Ltd. \\ Nottingham, United Kingdom \\ bruno.marques@ae-grp.co.uk
}

\begin{abstract}
The commutation angle, $\gamma$, of an interior permanent magnet synchronous motor's (IPMSM) vector diagram, plays an important role in compensating the back electromotive force; both under load phase current variations and/or when an extended speed range, being near the constant power range, is required by the application. This commutation angle is defined as the angle between the fundamental of the phase current and the fundamental of the back-emf. It can be utilized to provide a compensating effect in IPMSMs. This is due to the reluctance torque component being dependent on the phase current before the extended speed range. A real-time maximum torque per current and voltage strategy is employed to find the trajectory and optimum commutation angles, $\gamma$, where the level of accuracy depends on the application and available computational speed. A magnet volume reduction is proposed in this paper to minimize the permanent magnet mass to motor torque density, whilst maintaining the phase current below its maximum rated value. A mapping of $\gamma$ allows the determination of the optimum angles as shown in this paper. The $3^{\text {rd }}$ generation Toyota Prius IPMSM is considered the reference motor, where only the rotor configuration is altered to allow for an individual assessment. The electric vehicle's performance during acceleration and deceleration using various IPMSM rotor configurations is evaluated for a given four-wheel-drive vehicle. The powertrain uses two single-gear onboard, under standard drive cycles.
\end{abstract}

Keywords-AC machines, commutation angle mapping, electric vehicles, finite element analysis, drivability, inverter, synchronous motors, drives, field weakening

\section{NOMENCLATURE}

$\begin{array}{ll}\boldsymbol{v}_{\boldsymbol{d}}, \boldsymbol{v}_{\boldsymbol{q}} & d q \text {-axis voltages transposed fundamental abc voltages } \\ \boldsymbol{i}_{\boldsymbol{d}}, \boldsymbol{i}_{\boldsymbol{q}} & d q \text {-axis current transposed fundamental abc voltages } \\ \boldsymbol{L}_{\boldsymbol{d}}, \boldsymbol{L}_{\boldsymbol{q}} & d q \text {-axis inductances transposed fundamental abc voltages } \\ \boldsymbol{\lambda}_{\boldsymbol{m}} & \text { Flux linkage produced by permanent magnets } \\ \boldsymbol{R}_{\boldsymbol{s}} & \text { Stator winding phase resistance } \\ \boldsymbol{i}_{\boldsymbol{s}} & \text { Stator continuous current } \\ \boldsymbol{\omega}_{\boldsymbol{e}} & \text { Electrical angular velocity } \\ \gamma & \text { Commutation angle } \\ \boldsymbol{i}_{\boldsymbol{p} \boldsymbol{h}} & \text { Fundamental of the phase current } \\ \boldsymbol{e}_{\boldsymbol{p} \boldsymbol{h}} & \text { Fundamental electromotive force }\end{array}$

\begin{tabular}{ll}
$\boldsymbol{T}_{\boldsymbol{e}}$ & Electromagnetic torque \\
$\boldsymbol{I}_{\boldsymbol{m}}$ & Maximum current limited by the inverter \\
$\boldsymbol{V}_{\boldsymbol{m}}$ & Maximum voltage limited by the inverter \\
$\boldsymbol{R}_{\boldsymbol{w}}$ & Vehicle wheel radius \\
$\boldsymbol{\eta}_{\boldsymbol{t r a n s}}$ & Transmission efficiency \\
$\boldsymbol{G}_{\boldsymbol{r}}$ & Transmission gear ratio \\
$\boldsymbol{F}_{\boldsymbol{t}}$ & Total longitudinal (or resistive) force \\
$\boldsymbol{a}_{\boldsymbol{x}, \boldsymbol{m a x}}$ & Maximum longitudinal acceleration \\
$\boldsymbol{F}_{\boldsymbol{x}, \boldsymbol{F} / \boldsymbol{R}}$ & Front or rear longitudinal tire force in traction \\
$\boldsymbol{F}_{\boldsymbol{z}, \boldsymbol{F} / \boldsymbol{R}}$ & Vertical load on the front or rear axle \\
$\boldsymbol{g}$ & Gravitational acceleration \\
$\boldsymbol{m}_{\boldsymbol{a p p}}$ & Apparent mass of the rotating components of powertrain \\
$\boldsymbol{\vartheta}_{\boldsymbol{m a x}}$ & Maximum longitudinal road gradient \\
$\boldsymbol{T}_{\boldsymbol{m}, \boldsymbol{F} / \boldsymbol{R}}$ & Front or rear mechanical torque in traction \\
$\boldsymbol{m}_{\mathbf{0}}, \boldsymbol{m} \boldsymbol{1}$ & Vehicle gross mass and payload mass \\
$\boldsymbol{C}_{\boldsymbol{r}}$ & Rolling resistance coefficient \\
$\boldsymbol{T}_{\boldsymbol{m}, \boldsymbol{m a x}}$ & Maximum mechanical torque in traction \\
$\boldsymbol{T}_{\boldsymbol{r e f}}$ & Reference torque for controller to reach \\
$\boldsymbol{p}$ & Number of pole pairs \\
$\boldsymbol{T} \boldsymbol{P C A}$ & Maximum torque per commutation angle ratio \\
\hline
\end{tabular}

\section{INTRODUCTION}

\section{a) Motivation and Background}

In IPMSMs, the rotor design is one of the most complex parts; it can be noted that the rotor reluctance circuit with its specific permanent magnet (PM) arrangement strongly influences on the overall electromagnetic contribution of the powertrain. The complete system assessment is outside the scope of this paper, mainly focusing on changes to the rotor configuration. The embedded, or buried, nature of the permanent magnets provides mechanical rigidness, despite the significant centrifugal force at high speed, and produces a hybrid torque via a combination of magnet and reluctance contributions, resulting in high efficiencies over the complete torque-speed characteristic [1]. 


\section{b) Relevant Literature}

Numerous complex magnet arrangements have been proposed for achieving specific application-related performance characteristics [2-3]. For example, in [4], Guo and Parsa investigated the influence of straight, $\mathrm{V}$ - and $\mathrm{U}$ shaped magnet arrangements on the torque characteristics of IPMSMs. In [5], Dlala et al. considered the efficiency map of a PM machine with a V-shaped magnet layout and evaluated the achievable magnet size reduction. Ishikawa et al. [6] studied the dependency of the torque ripple on the shape and location of the permanent magnets. They implemented an optimization method using the response surface methodology to improve the vibrational aspects of the machines. Similarly, Jung et al. [7] successfully reduced the noise and vibrations of a specific machine prototype by optimising of the geometry of the magnet flux barriers.

Technically, IPMSMs, with a rotor saliency of $L_{q} L_{d}^{-1}>1$, can offer appealing performance characteristics, such as providing flexibility for adopting a variety of rotor geometries (spoked or embedded/buried magnets) as alternatives to nonsalient surface mounted synchronous machines. Buried magnets inside the rotor core provide the basis for a mechanically robust rotor construction capable of higher speeds since the permanent magnets are physically contained and protected inside the rotor lamination. Furthermore, in electromagnetic terms, introducing such laminated steel pole pieces above and next to the permanent magnets fundamentally alters the machine's reluctance circuit. This introduces a rotor saliency that can also reduce the PM volume in the IPMSMs while providing the same torque-speed operating range.

The complex nonlinear nature of an electric motor requires an optimized maximum torque per current and voltage MTPA/MTPV strategies to enhance the electric drive efficiency as this directly impacts range, and acceleration, and deceleration performance. Among all published approaches [8-12], (i) mathematical-based methods [8-9], (ii) look-up table methods [10], (iii) online search methods using optimization methods [11], and (iv) signal injection methods [12] are the most popular strategies. Depending on the level of complexity, each approach offers some advantages in terms of computational time and accuracy of the selected strategy. Most analytical-based techniques like (i) and (ii) neglect the partial derivatives of the IPMSMs subjected to the commutation angle. Using such strategies limits the MTPA/MTPV ability to compute the operation points accurately, and thus, deviations that occur from the optimum torque or efficiency are likely to occur. Recently, approaches (iii) and (iv) have become very popular due to their ability to provide increased electric drive efficiencies.

\section{c) Contributions and Organization}

In this paper, the impacts of rotor configurations are sought after using the stator continuous current and back-EMF vector diagrams. Various interior permanent magnet (IPM) rotor configurations are assessed for a pure electric vehicle (EV) with an all-wheel-drive configuration. The commutation angle maps for every IPM rotor configuration, as presented in Fig. 1, are investigated to introduce a factor that represents the highest maximum torque per commutation angle. Following the selection of the "best" IPMSM, a finite element analysis (FEA) is performed to verify the results with the EV drivability indexes at the vehicle level, to determine whether the proposed analytical factor is valid to make initial predictions on which IPM rotor configuration can deliver an improved vehicle acceleration and longitudinal road gradient capabilities. The vehicle configuration is shown in Fig. 3, and the EV dynamics are given in Table I. The paper objectives are: (i) to map the energy efficiencies and commutation angles, $\gamma$, variations and study its impact on the efficiency that is mapped on the torque-speed profile using a 2-D FEA of various embedded/buried IPM rotor configurations; (ii) each rotor configuration's capacity is analysed, subject to its drivability metrics such as vehicle acceleration and longitudinal road gradient.

The EV considered in this study is a four-wheel-drive electric passenger car with two identical onboard IPMSMs, one per axle. Each IPMSM is coupled to the two wheels of the axle through a single-speed mechanical transmission with an open differential, half-shafts, and constant velocity joints; and (iii) introducing a new factor reporting the maximum torque per commutation angles (TPCA) for all three main regions, low speed, accelerating, and high-speed operations. The $3^{\text {rd }}$ generation Toyota Prius (T-Prius) IPMSM is considered as the reference motor for this study. All the studied IPMSMs are assessed under both urban and motorway drive cycles to evaluate the vehicle's drivability performance during acceleration and deceleration.

\section{ANALYTICAL AND NUMERICAL MODELLING}

Mathematically, considering the fundamental waveforms, the IPMSMs are well formulated [13-14], in which the $d-q$ axis voltages under the steady-state condition are:

$$
\left[\begin{array}{l}
v_{d} \\
v_{q}
\end{array}\right]=\left[\begin{array}{cc}
R_{S} & -\omega_{e} L_{q} \\
\omega_{e} L_{q} & R_{S}
\end{array}\right]\left[\begin{array}{c}
i_{d} \\
i_{q}
\end{array}\right]+\left[\begin{array}{c}
0 \\
\omega_{e} \lambda_{m}
\end{array}\right]
$$

The commutation angle for $d q$-axis currents:

$$
\left\{\begin{array}{c}
i_{d}=-i_{s} \sin \gamma \\
i_{q}=i_{s} \cos \gamma
\end{array}\right.
$$

where the fundamental electromotive force, $e_{p h},\left(\gamma=\left(i_{p h}, e_{p h}\right)\right)$.

The electromagnetic, $T_{e}$, can be calculated using [13-14]:

$$
T_{e}=\frac{3}{2} p\left[\lambda_{m}+\left(L_{d}-L_{q}\right) i_{d}\right] i_{q}
$$

with consideration of the partial derivative of commutation angle, $\gamma$ :

$$
\begin{aligned}
& \frac{\partial T_{e}}{\partial \gamma}=\frac{3 p}{2}\left[-\lambda_{m} i_{s} \sin \gamma+\frac{\partial \lambda_{m}}{\partial \gamma} i_{s} \cos \gamma-L_{d} i_{s}^{2} \cos 2 \gamma+L_{q} i_{s}^{2} \cos 2 \gamma-\right. \\
& \left.\frac{\partial L_{d}}{\partial \gamma} \frac{i_{s}^{2}}{2} \sin 2 \gamma+\frac{\partial L_{q}}{\partial \gamma} \frac{i_{s}^{2}}{2} \sin 2 \gamma\right]
\end{aligned}
$$

A real-time maximum torque per current (MTPA) and maximum torque per voltage (MTPV) control strategy is employed to satisfy the EV driver demands. Such a strategy is reported in [15], where the authors used the rate of change of the parameters of the IPMSM's of Eq. 1-3 to optimize the working criteria of both MTPA and MTPV strategies using a Lagrange multiplier. This multi-objective problem is defined:

$$
\min f\left(i_{d}, i_{q}\right)=f_{1}+f_{2}
$$

The first objective is the MTPA which can be computed as an optimization problem using [15]:

$$
\min f_{1}\left(i_{d}, i_{q}\right)=\left(-i_{s} \sin \gamma\right)^{2}+\left(i_{s} \cos \gamma\right)^{2}
$$

subject to the following constraint:

$$
\text { s.t. }\left\{\begin{array}{c}
T_{\text {ref }}-\frac{3}{2} p\left[\lambda_{m}+\left(L_{d}\left(i_{d}, i_{q}\right)-L_{q}\left(i_{d}, i_{q}\right)\right) i_{d}\right]=0 \\
i_{d}^{2}+i_{q}^{2} \leq I_{m}^{2}
\end{array}\right.
$$

The second objective is to satisfy the MTPV trajectory based on the following cost function [15]: 


$$
\min f_{2}\left(i_{d}, i_{q}\right)=v_{d}^{2}+v_{q}^{2}
$$

subjected to the following constraint:

$$
\text { s.t. }\left\{\begin{array}{c}
T_{r e f}-\frac{3}{2} p \lambda_{q}\left[\frac{\lambda_{m}}{L_{q}\left(i_{d}, i_{q}\right)}+\lambda_{d}\left(\frac{1}{L_{q}\left(i_{d}, i_{q}\right)}-\frac{1}{L_{q}\left(i_{d}, i_{q}\right)}\right)\right]=0 \\
\sqrt{v_{d}^{2}+v_{q}^{2}} \leq V_{m}
\end{array}\right.
$$

The objective function minimization is essentially a torque maximization at a certain speed within the constant torque region (below base speed) once the torque demand is satisfied by considering the limitations of phase or line-to-line voltages and currents or by altering the commutation angle. By increasing the speed demand (above base speed), the torque demand could be achieved by decreasing the phase current (recall that in a star connected winding phase and line current are the same) below the maximum allowed value or by altering the commutation angle.

In the numerical FEA modelling, the stator topology and specification are fixed based on a $3^{\text {rd }}$ generation Toyota Prius motor and reported in Table I for the fairness of the study. The rotor configurations are only changed via different IPM magnet arrangements, and these parameters are summarized in Table II. In tables I and II, the main dimensional parameters are selected based on the original $3^{\text {rd }}$ generation Toyota Prius motor. Some parameters are defined within a range; all design variables are constrained to the reference motor's maximum magnet volume, such as $W_{w 1}, T_{m}, L_{m}, V_{p m}$, and $W_{m}$. As shown, some of the magnet-related parameters are defined in a range for the design of experiment/regression (DOE/R) sensitivity analysis [16] in a pre-processing stage to discover the best values for these PM-related dimensional parameters. In this study, one of the sensitivity objectives is to reduce the overall PM volume $V_{p m}$ for the new $\mathrm{V}$ arrangements (Rotors $2 \& 3$ ). This consideration is performed only for the second

TABle I MAIN Stator PARAmeters

\begin{tabular}{c|c|c|c}
\hline \hline Parameter & Description & Unit & Value \\
& & \\
\hline$D_{s i}$ & Inner stator diameter & $\mathrm{mm}$ & 161.9 \\
$D_{s o}$ & Outer stator diameter & $\mathrm{mm}$ & 264 \\
$H_{s}$ & Slot height & $\mathrm{mm}$ & 30.9 \\
$W_{s}$ & Slot width & $\mathrm{mm}$ & 6.69 \\
$H_{1}$ & Intermediary height of the slot & $\mathrm{mm}$ & 0.27 \\
$L$ & Axial length & $\mathrm{mm}$ & 50 \\
$L_{g}$ & Airgap length & $\mathrm{mm}$ & 0.75 \\
$N_{s}$ & Number of slots & - & 48 \\
$R$ & Slot bottom radius & $\mathrm{mm}$ & 3.345 \\
$V$ & Undercut angle of stator tooth tip & $\mathrm{deg}$ & 20.298 \\
$W_{s 2}$ & Top slot width & $\mathrm{mm}$ & 6.69 \\
$W_{s 1}$ & Bottom slot width & $\mathrm{mm}$ & 3.34 \\
$W_{T 1}$ & Tooth width, upper part of slot & $\mathrm{mm}$ & 7.45 \\
$W_{T 2}$ & Tooth width, bottom part of slot & $\mathrm{mm}$ & 7.502 \\
$W_{o}$ & Width of slot opening & $\mathrm{mm}$ & 1.88 \\
$H_{o}$ & Height of slot opening & $\mathrm{mm}$ & 1.22 \\
\hline \hline
\end{tabular}

TABLE II MAIN Rotor PARAMETERS WITH THE PM SIZE RANGES

\begin{tabular}{c|c|c|c|c}
\hline \hline Parameter & Description & Unit & T.Prius & Rotor 2 \& 3 \\
\hline$D_{r o}$ & Outer rotor diameter & $\mathrm{mm}$ & 160.4 & 160.4 \\
$D_{r i}$ & Inner rotor diameter & $\mathrm{mm}$ & 110 & 110 \\
$p$ & Number of poles & - & 8 & 8 \\
$W_{w 1}$ & Window width & $\mathrm{mm}$ & 0.7 & $0.2-1.2$ \\
$T_{m}$ & Magnet thickness & $\mathrm{mm}$ & 7.16 & $2-7.16$ \\
$T_{1}$ & Thickness of rotor yoke & $\mathrm{mm}$ & 8.14 & 8.14 \\
& under the magnet & & & \\
$L_{m}$ & Axial length of magnet & $\mathrm{mm}$ & 50 & $45-50$ \\
$V_{p m}$ & Magnet volume & $\mathrm{cm}^{3}$ & 6.401 & $3-6.4$ \\
$V_{p}$ & Angular pitch & $\mathrm{deg}$ & 45 & 45 \\
$W_{m}$ & Magnet width & $\mathrm{mm}$ & 17.88 & $14-25$ \\
\hline \hline
\end{tabular}

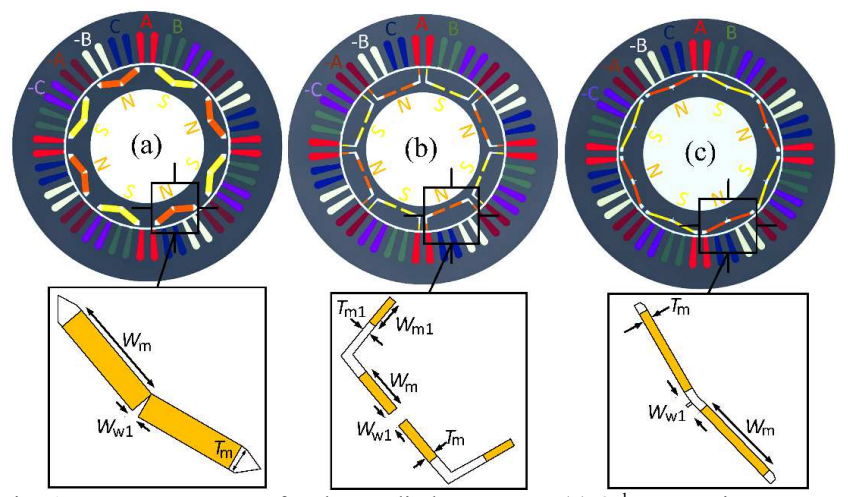

Fig. 1 PM arrangements for the studied IPMSMs, (a) $3^{\text {rd }}$ Generation Toyota Prius or reference model, (b) modified V1, and (c) modified V2.
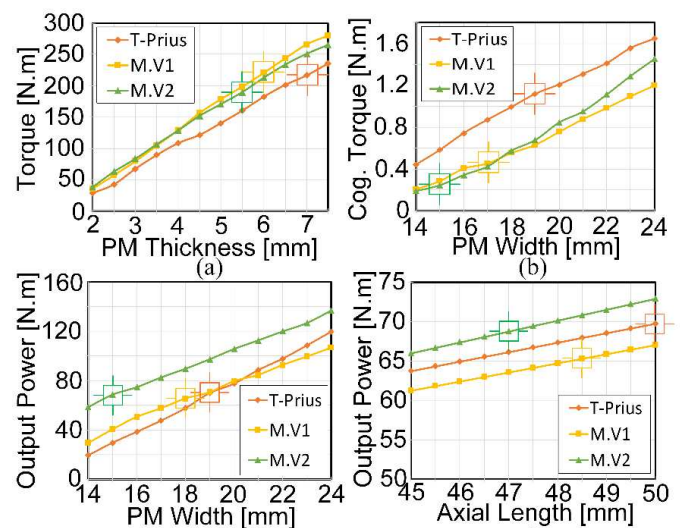

(c)

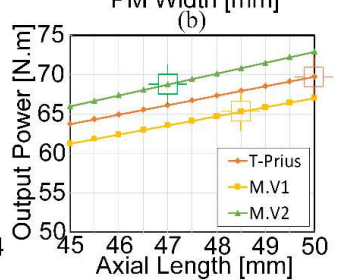

(d)

Fig. 2 Sensitivity analysis for magnet sizing, considering (a) electromagnetic torque vs. PM thickness, (b) cogging toque ripple (peak-to-peak) vs. PM width, (c) output power vs PM width, (d) output power vs. axial length. The marked squares show the selected parameter values for each configuration.

and third rotors, but not the 3rd generation Toyota Prius reference rotor.

Fig. 1 demonstrates the studied IPMSMs with different rotor configurations, in which the second and third rotors are derived from $\mathrm{V}$ type magnet arrangements. The dimensions of both new second and third rotors are selected from the DOE/R sensitivity analysis, where the PM-focused trends are presented in Fig. 2. The impact of the PM thickness, $T_{m}$, on the maximum electromagnetic torque at the base speed is demonstrated in Fig.2 (a). Interestingly, the modified V1 (or M.V1) rotor can produce approximately the same torque with $1 \mathrm{~mm}$ less magnet thickness, i.e. $12 \%$ less magnet volume than T-Prius (reference rotor). While M.V2 has shown a similar trend as M.V1 in terms of torque production, it can also be reported that the lowest peak-to-peak cogging torque is obtained by M.V2, with a $15 \mathrm{~mm}$ magnet width. Both new rotors, M.V1 and M.V2, have a reduced peak-to-peak cogging torque (see Fig. 2(b)). Similarly, M.V2 has the same output power capability, using less PM width by $4 \mathrm{~mm}$, in contrast with the T.Prius rotor, as shown in Fig. 2(c). As the axial length of the PMs varies between $45-50 \mathrm{~mm}$, again M.V2 model exhibits almost the same power as the reference motor, with $3 \mathrm{~mm}$ shorter PM axial length $L_{m}$. The purpose of the sensitivity is to find the influence of PM-related parameters, with a possible reduction of $V_{p m}$. In Fig. 2, the squared markings show how to obtain almost the same performance as the reference motor. Note that in this study, several simplifications have been made. For example, manufacturing tolerances, material availability, transient temperature effects, lamination material variations, radii chamfering, 3D magnetic effects, mechanical deformations and high-speed safety 
criteria, the influence of rotor press-fit. These final selections show a considerable magnet volume per pole reduction, in which $6.401 \mathrm{~cm}^{3}, 4.998 \mathrm{~cm}^{3}, 3.877 \mathrm{~cm}^{3}$ can be reported, i.e. $12 \%$ and $40 \%$. At least illustrating that a potential further material price reduction could be possible while maintaining the same performance factors.

\section{RESUlts For COMMUTATION ANGLE MAPS EVAluAtion}

\section{A. FEA-based Results for EVS}

The studied IPMSMs are mapped for a better applicationoriented understanding of the optimum selection of the commutation angles. The section aims is to evaluate the electromagnetic capability, including efficiency and commutation angle maps, of both new developed IPMSM models, which ultimately allow a trade-off discussion considering the vehicle power demand. All simulations are performed using 2D FEA using the same materials without considering the various variations mentioned previously. Furthermore, both motoring and generating efficiencies, which can be different in practice, are assumed to be identical for simplicity.

Fig. 3 presents the electric vehicle (EV) configuration. In this vehicle, two on-board IPMSMs, IPMSM1 and IPMSM2 at the rear and forward wheel drives, deliver the traction force for the four-wheel-drive electric passenger car with two single-gear onboard powertrains $[13,18]$. Also, the vehicle utilises an electric continuously variable transmission system. Two different suspension systems are employed for the rear and forward wheels. The front wheel is a MacPherson strut with an anti-roll bar, coil springs and dampers. The rear suspension system is a Torsion beam with coil springs and dampers. The high-voltage battery unit type is Nickel-metal hydride, with a nominal voltage of $201.6 \mathrm{Vdc}$ and a capacity of $6.5 \mathrm{Ah}$. The vehicle's maximum speed is $112 \mathrm{mph}$ with 0 $62 \mathrm{mph}$ acceleration in $10.4 \mathrm{sec}$. More details of the vehicle dynamics are summarized in Table III, in which most of the parameters are the same as Toyota Prius car.

Fig. 4 illustrates the efficiency maps produced by the studied IPMSMs to assess the premium efficiency region $(\geq 0.94)$ offered by each rotor configuration. The focus is to obtain the greatest premium efficiency region within both the constant torque and the constant power regions for all passenger vehicles. In Fig. 4(a), the efficiency map of the reference motor shows a wide premium region between starting torque (maximum $211.6 \mathrm{Nm}$ ) and the low speed and accelerating regions. In the T-Prius motor, a PM-related torque density of $4.13 \mathrm{Nm} / \mathrm{cm}^{3}$ can be reported. The torque production has decreased to $193.5 \mathrm{Nm}$, in the modified V1 motor, presented in Fig. 4(b). However, the torque density has slightly improved to $4.84 \mathrm{Nm} / \mathrm{cm}^{3}$. In this configuration, the premium efficiency region has been reduced. In the proposed rotor configuration, the M.V2 motor, with the maximum torque of $200.5 \mathrm{Nm}$, and a torque density improvement of $6.46 \mathrm{Nm} / \mathrm{cm}^{3}$, has shown a better usage of PMs. Additionally, the premium efficiency region is slightly enhanced compared

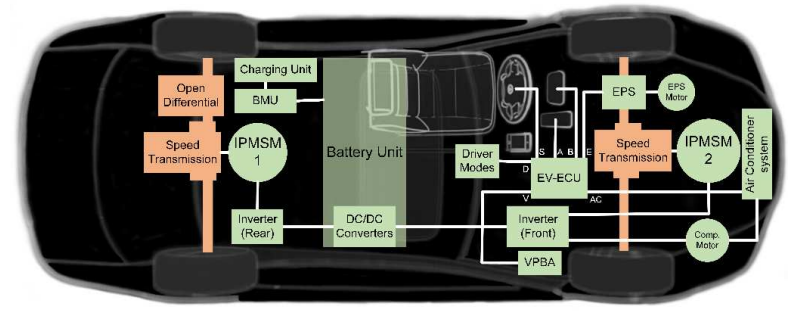

Fig. 3 Schematic of the considered EV layout. to the other two models, (see Fig. 4(c)). The operating points are scattered for three different standard drive cycles: (i) US06, (ii) Artemis Urban, and (iii) Artemis HighWay. The US06 cycle is an aggressive, high speed (max $129.2 \mathrm{~km} / \mathrm{h}$ ) and/or high acceleration driving behaviour, rapid speed fluctuations, and driving behaviour following start-up. Artemis cycles are produced based on European real-world driving patterns, where the Artemis_Urban and Artemis_HighWay reach $57.3 \mathrm{~km} / \mathrm{h}$ and $131.4 \mathrm{~km} / \mathrm{h}$.

Fig. 5 presents the commutation angle maps for the studied IPMSMs, where the maps are generated to show the EV's operating points between 0 to $212 \mathrm{Nm}$ with intervals of $5 \mathrm{Nm}$. As a result of curve fitting a variable current amplitude, and commutation angle and corresponding control trajectory, the maps are provided for a better understanding of the $\gamma$ angle distribution within the torque-speed profile when an

TABLE III ELECTRIC VEHICLE SPECIFICATIONS

\begin{tabular}{l|l|c|c}
\multicolumn{1}{c}{ TABLE III ELECTRIC VEHICLE SPECIFICATIONS } \\
\hline \hline Params & \multicolumn{1}{c}{ Description } & Unit & Value \\
\hline$m_{0}$ & Vehicle mass & $\mathrm{kg}$ & 1805 \\
$m_{1}$ & Payload & $\mathrm{kg}$ & 500 \\
$L_{T}$ & Total length & $\mathrm{mm}$ & 4460 \\
$h_{T}$ & Total height & $\mathrm{mm}$ & 1490 \\
$W_{T}$ & Total width & $\mathrm{mm}$ & 1745 \\
$A$ & Frontal area & $\mathrm{m}^{2}$ & 2 \\
$L$ & Wheelbase & $\mathrm{m}$ & 2.7 \\
$a$ & Front semi-wheelbase & $\mathrm{m}$ & 1.3 \\
$H_{C G}$ & Center of gravity height & $\mathrm{m}$ & 0.5 \\
$R_{w}$ & Wheel radius & $\mathrm{m}$ & 0.381 \\
$C_{d}$ & Aerodynamic drag coefficient & - & 0.25 \\
$C_{r}$ & Rolling resistance coefficient & - & 0.015 \\
$K$ & Rolling resistance coefficient & $\mathrm{s}^{2} / \mathrm{m}^{2}$ & $6.5 \mathrm{e}-6$ \\
$S R$ & Steering ratio & - & $14.6: 1$ \\
\hline \hline
\end{tabular}

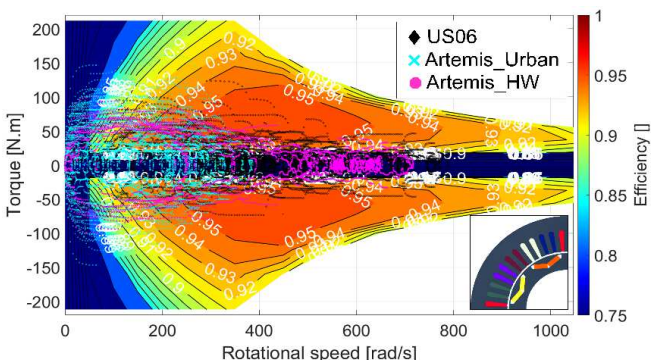

(a)

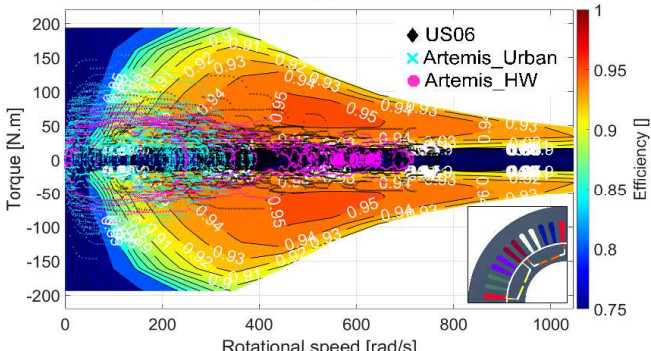

(b)

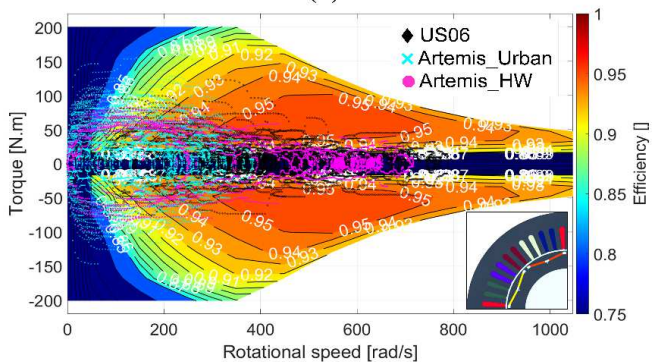

(c)

Fig. 4 Torque-speed-efficiency maps for the studied IPMSMs, (a) Toyota Prius IPMSM, (b) M.V1, and (c) M.V2; under US06, Artemis_Urban, and Artemis HighWay cycles. 

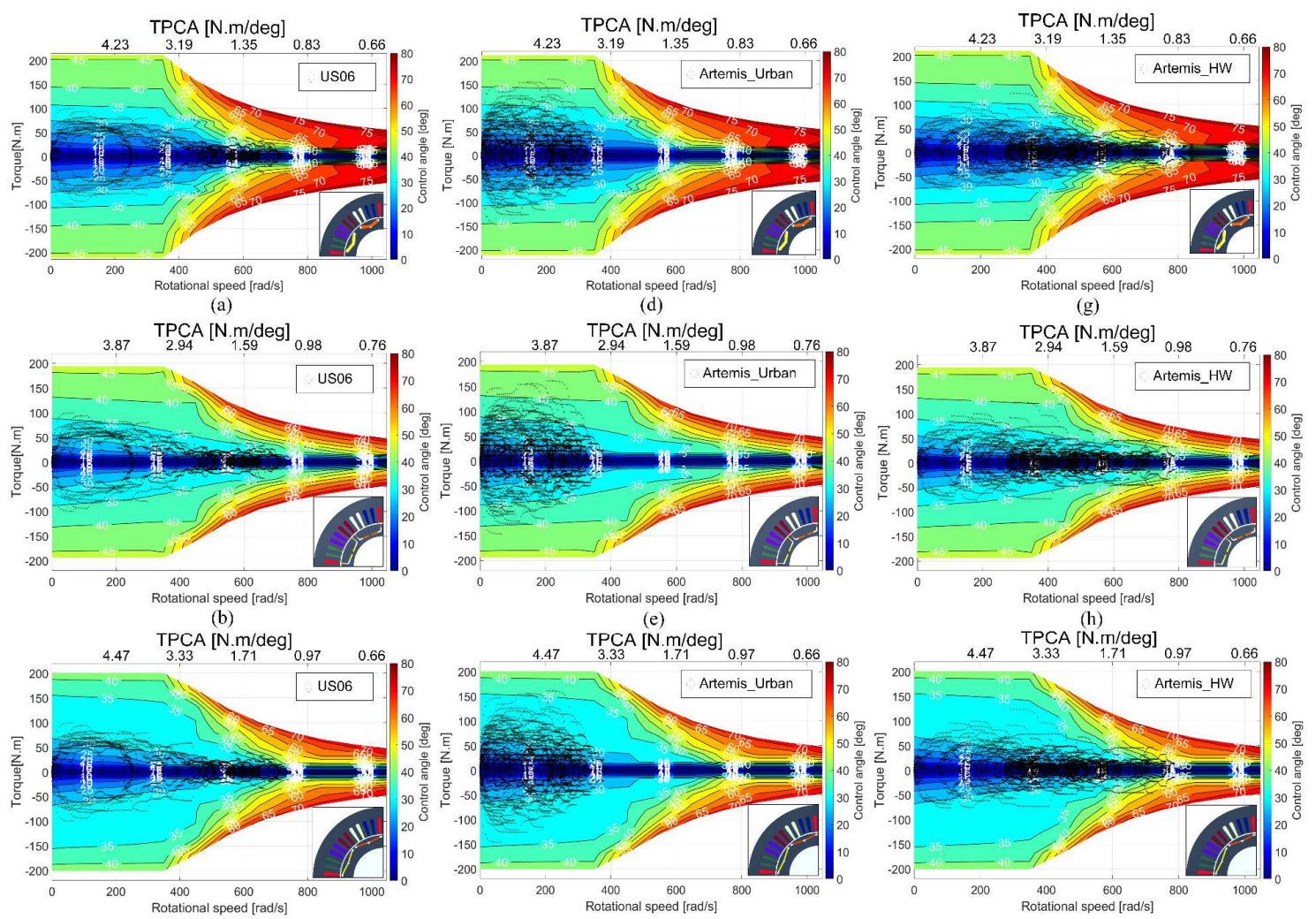

(c)

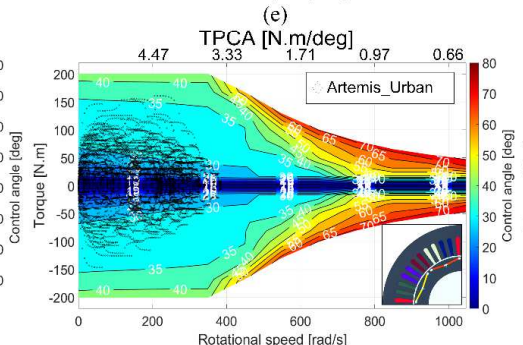

(f)

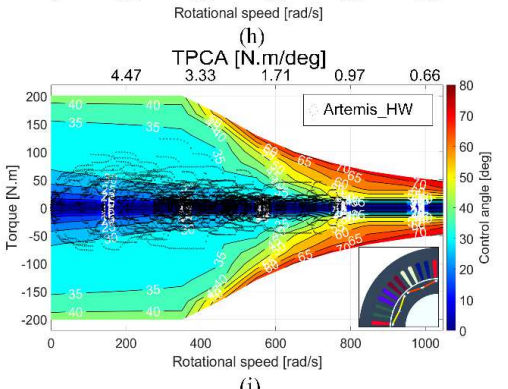

(i)

Fig. 5 Commutation angle maps for IPMSMs, considering TPCA factor, under (a) Toyota Prius or reference model under US06, (b) M.V1 under US06, (c) M.V2 under US06, (d) Toyota Prius under Artemis Urban, (e) M.V1 under Artemis Urban, (f) M.V2 under Artemis Urban, (g) Toyota Prius under Artemis HighWay, (h) M.V1 under Artemis HighWay, and (i) M.V2 under Artemis HighWay.

identical MTPA/MTPV control strategy is used for all the IPMSMs. From the machine's characteristics, it is obvious that the premium efficiency area is concentrated with the minimized commutation angle since this minimizes the total power loss. In these graphs, the commutation angle strategy maps are presented for different driving modes: (i) urban, (ii) rural-urban, and (iii) motorway. Under the US06 cycle, most operating points have fallen within the lowest $\gamma$, indicating the premium efficiency region. Therefore, the proposed M.V2 has shown the highest premium efficiency coverage. Under the Artemis Urban cycle, both Toyota Prius and M.V2 machines have performed equally well to drive the highest number of operating points within the premium efficiency. During the Artemis HighWay cycle, the M.V2 has included the most operating points at the premium efficiency region compared to the Toyota Prius machine. The proposed M.V2 model has displayed the largest premium efficiency region, particularly at high speeds, beyond the demand speeds of all the drive cycles considered, see Fig. 4(c). M.V2 model used the lowest overall commutation angle, see Fig. 5.

A new factor TPCA is defined for all three main operational regions. This ratio measures the maximum torque produced over the resulted commutation angle $\gamma$ at every specific speed demand. As the speed increases, the inverter injects a higher phase current amplitude and commutation angle to produce the required torque from the vehicle's throttle. The angle $\gamma$ varies linearly in the constant torque region; however, it rises nonlinearly during the accelerating phase. The TCPA is calculated for each IPMSM configuration, and the proposed M.V2 motor achieved the highest TPCA of 4.47 . by the proposed M.V2 motor. During the accelerating phase (between 380-650rad/s or 3629-6207rpm), the highest TPCA of 5.04 is again obtained for the proposed M.V2 motor. Toyota Prius and M.V1 models have shown similar TPCA of approx. 4.54. During high-speed operations (between 650$1000 \mathrm{rad} / \mathrm{s}$ or $6207-10000 \mathrm{rpm})$, the lowest TPCA is reported for the Toyota Prius machine, the M.V1 model offers the highest TPCA. Overall, within all three regions, the proposed M.V2 has achieved the highest TPCA of 11.14 compared to the other two models.

\section{B. Drivability and Electromagnetic Factors Trade-offs}

In this section, the longitudinal acceleration and road gradient factors represent the drivability performance of the EV, based on [13,16-17]. Both factors are simulated considering a tire-road friction $\mu_{\max }=10$ and zero slope. As two IPMSMs are used in front (F) and rear (R) axles, hence the torque at each IPMSM, using a backward-facing vehicle drivetrain model, is:

$$
T_{m}=\left\{\begin{array}{c}
\frac{1}{2} \frac{F_{t} R_{w}}{\eta_{\text {trans }} G_{r}}, \text { if } F_{t} \geq 0 \\
0, \text { if } F_{t}<0
\end{array}\right.
$$

The maximum longitudinal acceleration $a_{x, \max }$ is computed, as an optimization problem, under the assumption that the front-to-total motor torque distribution can vary with respect to the intervention of a traction controller that prevents wheel spinning on the critical axle:

$$
\left\{\begin{array}{cc}
a_{x, \max }=\max _{T_{m, F}, T_{m, R}} \frac{\left(T_{m, F}+T_{m, R}\right) G_{r} \eta_{\text {trans }}-C_{r}\left(m_{0}+m_{1}\right) g R_{W}}{\left(m_{0}+m_{\text {app }}+m_{1}\right) R_{w}} \\
\text { s.t. } \\
T_{m, F / R} \leq T_{m, \max } \\
\frac{F_{x, F / R}}{F_{z, F / R}} \leq \mu_{\max }
\end{array}\right.
$$


The next drivability-related factor is the maximum longitudinal road gradient, $\vartheta_{\max }$ :

$$
\left\{\begin{array}{c}
\vartheta_{\max }=\max _{T_{m, F}, T_{m, R}} \vartheta \\
\text { s.t. } \\
\frac{\left(T_{m, F}+T_{m, R}\right) G_{r} \eta_{\text {trans }}}{R_{w}}-\left(m_{0}+m_{1}\right) g \sin (\vartheta) \\
-C_{r}\left(m_{0}+m_{1}\right) g \cos (\vartheta)=0 \\
T_{m, F / R} \leq T_{\max } \\
\frac{F_{x, F / R}}{F_{z, F / R}} \leq \mu_{\max }
\end{array}\right.
$$

where the vehicle can travel at very low speed and zero longitudinal acceleration.

Table IV reports the main parameters resulted from the drivability factors and the FEA-focused electromagnetic analysis for each IPMSM. As given, the average machine's efficiencies are $94.1 \%, 93.8 \%, 94.9 \%$ for T-Prius, M.V1, and M.V2 models, respectively. These results demonstrate that the proposed M.V2 model has shown the best performance in drivability and electromagnetic-based investigations. It is important to mention a significant reduction in magnet size in both M.V1 and M.V2 models by $22.0 \%$ and $39.4 \%$, respectively, compared to the 3 rd generation Toyota Prius vehicle. Consequently, this leads to a substantial decrease in the machine's material cost.

TABLE IV DRIVABILITY AND ELECTROMAGNETIC MAIN FACTORS

\begin{tabular}{|c|c|c|c|c|}
\hline \multicolumn{2}{|c|}{ Parameters/models } & T-Prius & M.V1 & M.V2 \\
\hline \multicolumn{5}{|c|}{ Drivability and Efficiency Factors } \\
\hline \multirow{3}{*}{$\bar{\eta}_{m}[\%]$} & US06 & 95.0 & 94.2 & 95.0 \\
\hline & Artemis_Urban & 95.0 & $\overline{93.8}$ & 95.5 \\
\hline & Artemis HW & $\underline{92.5}$ & $\overline{93.5}$ & 94.4 \\
\hline \multicolumn{2}{|c|}{$\begin{array}{c}a_{x, \max }\left[\mathrm{m} / \mathrm{s}^{2}\right] \\
\vartheta_{\max }[\mathrm{deg}]\end{array}$} & $\begin{array}{l}\overline{7.55} \\
42.8 \\
\end{array}$ & $\frac{7.41}{42.8}$ & $\begin{array}{l}7.67 \\
43.6\end{array}$ \\
\hline \multicolumn{5}{|c|}{ Electromagnetic Factors } \\
\hline \multicolumn{2}{|c|}{ TPCA $[\mathrm{Nm} / \mathrm{deg}]$} & 10.3 & 10.1 & 11.1 \\
\hline \multicolumn{2}{|c|}{$T_{e} / V_{p m}\left[\mathrm{Nm} / \mathrm{cm}^{3}\right]$} & $\underline{4.13}$ & $\overline{4.84}$ & 6.46 \\
\hline \multicolumn{2}{|c|}{$T_{\max }$ in PMs at base speed $\left[{ }^{\circ} \mathrm{C}\right]$} & $\overline{69.7}$ & 67.8 & 66.9 \\
\hline \multicolumn{2}{|c|}{$P_{\text {out }, \max }[\mathrm{kW}]$} & $\overline{69.6}$ & 60.3 & $\underline{59.4}$ \\
\hline \multicolumn{2}{|c|}{ Power factor at base speed [-] } & 0.96 & $\underline{0.94}$ & 0.99 \\
\hline \multicolumn{2}{|c|}{$\beta_{\max }$ at base speed $[\mathrm{deg}]$} & $\underline{50.2}$ & 50.1 & 45.2 \\
\hline
\end{tabular}

Notes: Bold text indicates the best performance among the studied IPMSMs, whereas underlined text shows the worst performance.

\section{CONCLUSION}

This study offers a comprehensive guide for the optimal selection of magnet arrangement and drives for the IPMSMs used in traction application such as EVs. Two new IPMSM rotor configurations are proposed and compared with the $3^{\text {rd }}$ generation Toyota Prius IPMSM with fixed stator configuration. The newly developed rotors based on the magnet arrangements, M.V1 and M.V2 models, are sized using DOE/R sensitivity analysis. The efficiency and commutation angle maps were provided for the first time to better understanding the operating MTPA/MTPV strategy within the wide speed range operations. The main results achieved with the proposed M.V2 model are: (i) the torque density improvement by $36 \%$, while the PMs use was reduced; (ii) which will contribute to IPMSM material cost reduction; (iii) better rotor dynamic has resulted in lowering the cogging torque significantly; (iv) the only undesired finding is the maximum output power capability which has decreased by $14.69 \%$; (v) higher electric drive efficiency at the vehicle level over the entire three drive cycles by $0.84 \%$ (in average), in which the maximum inverter current is $125 \mathrm{~A}$ for the studied IPMSMs; (vi) enhanced maximum longitudinal acceleration at the vehicle level by $1.59 \%$; finally (vii) the maximum longitudinal road gradient improvement by $1.85 \%$ at the vehicle level. All the IPMSMrelated simulations are carried using 2-D FEA.

\section{REFERENCES}

[1] N. Bianchi and T. Jahns, "Design, analysis, and control of interior pm synchronous machines," IEEE-IAS Electrical Machines Committee, Oct. 2004, Seattle, Washington State, USA

[2] S. Hong and I. Park, "Continuum sensitivity-based optimization of interior permanent magnet synchronous motor with shape constraint for permanent magnet," IEEE Transactions on Magnetics, vol. 56, no. 2, pp. 1-4, Feb. 2020.

[3] J. Du, X. Wang, and H. Lv, "Optimization of magnet shape based on efficiency map of IPMSM for EVs," IEEE Transactions on Applied Superconductivity, vol. 26, no. 7, pp. 1-7, Oct. 2016.

[4] L. Guo and L. Parsa, "Effects of magnet shape on torque characteristics of interior permanent magnet machines," IEEE Electric Ship Technologies Symposium, pp. 1-7, Apr. 2009.

[5] E. Dlala, M. Solveson, S. Stanton, Z. Tang, M. Christini, R. Ong, and B. Peaslee, "Efficiency map simulations for an interior PM motor with experimental comparison and investigation of magnet size reduction," IEEE Int. Electric Machines Drives Conference, pp. 1-7, Chicago, USA, May 2013

[6] T. Ishikawa, M. Yamada, and N. Kurita, "Design of magnet arrangement in interior permanent magnet synchronous motor by response surface methodology in consideration of torque and vibration," IEEE Trans. on Magnetics, vol. 47, no. 5, pp. 1290-1293, 2011.

[7] J. Jung, S. Lee, G. Lee, H. J.P., D. Lee, and K. Kim, "Reduction design of vibration and noise in IPMSM type integrated starter and generator for hev," IEEE Trans. on Mgn, vol. 46, no. 6, pp. 2454-2457, 2010.

[8] C. Lai, G. Feng, J. Tjong, and N. C. Kar "Direct Calculation of Maximum-Torque-Per-Ampere Angle for Interior PMSM Control Using Measured Speed Harmonic," IEEE Trans. on Power Elec., vol. 33, no. 11, pp. 9744-9752, 2018.

[9] K. Li, and Y. Wang "Maximum Torque Per Ampere (MTPA) Control for IPMSM Drives Based on a Variable-Equivalent-Parameter MTPA Control Law," IEEE Trans. on Power Elec., vol. 34, no. 7, pp. 70927102,2018

[10] S.-Y. Jung, J. Hong, and K. Nam, "Current minimizing torque control of the IPMSM using ferrari's method," IEEE Trans. Power Elec., vol. 28, no. 12, pp. 5603-5617, Dec. 2013.

[11] L-Jay Cheng, and M-Ching Tsai "Robust Scalar Control of Synchronous Reluctance Motor With Optimal Efficiency by MTPA Control,” IEEE Access, vol. 9, pp. 32599 - 32612, 2021.

[12] R. Antonello, M. Carraro, and M. Zigliotto, "Maximum-torque-per ampere operation of anisotropic synchronous permanent-magnet motors based on extremum seeking control," IEEE Trans. Ind. Electron., vol. 61, no. 9, pp. 5086-5093, Sep. 2014.

[13] P. Asef, R. Bargallo, A. Lapthorn, D. Tavernini, L. Shao, and A. Sorniotti, "Assessment of the Energy Consumption and Drivability Performance of an IPMSM-Driven Electric Vehicle Using Different Buried Magnet Arrangements," Energies. vol. 14, no. 1418, pp. 1-22, Mar 2021.

[14] J. Lemmens, P. Vanassche, P., and J. Driesen, "PMSM Drive Current and Voltage Limiting as a Constraint Optimal Control Problem," IEEE J. Emerg. Sel. Top. Pow. Elec., vol. 3, pp. 326-338, 2014.

[15] Z. Xia, S. Nalakath, R. Tavirdilu-Asl, Y. Sun, J. Wiseman, and A. Emadi, "Online Optimal Tracking Method for Interior Permanent Magnet Machines with Improved MTPA and MTPV in Whole Speed and Torque Ranges," IEEE Trans. Pow. Elec.., vol. 35, pp. 9753-9769, 2020.

[16] P. Asef, and A. Lapthorn, "Overview of Sensitivity Analysis Methods Capabilities for Traction AC Machines in Electrified Vehicles," IEEE Access, vol. 9, pp. 23454-23471, 2021

[17] S. D. Pinto, P. Camocardi, A. Sorniotti, P. Gruber, P. Perlo; F. Viotto, "Torque-Fill Control and Energy Management for a Four-Wheel-Drive Electric Vehicle Layout With Two-Speed Transmissions," IEEE Trans. Ind. Appl., vol. 53, no. 1, pp. 447-458, Feb. 2017.

[18] S. D. Pinto, P. Camocardi, C. Chatzikomis, A. Sorniotti, F. Bottiglione, G. Mantriota, P. Perlo, "On the Comparison of 2- and 4-Wheel-Drive Electric Vehicle Layouts with Central Motors and Single- and 2-Speed Transmission Systems," Energies, vol.13, no.3328, pp. 1-22, 2020. 